\title{
Conhecimento tradicional e o ensino de Ciências: uso de cará- roxo (Dioscorea trifida) como indicador de ácidos e bases
}

\author{
Traditional knowledge and science teaching: use of cara yam (Dioscorea \\ trifida) for acids and bases indicator \\ Conocimientos tradicionales y enseñanza de las ciencias: uso del ñame \\ rojo (Dioscorea trifida) como indicador de ácidos y bases
}

\author{
Edriely Vilena de Oliveira (edryvilena11@gmail.com) \\ Instituto de Saúde e Biotecnologia, Universidade Federal do Amazonas. \\ Klenicy Kazumy de Lima Yamaguchi (klenicy@gmail.com) \\ Instituto de Saúde e Biotecnologia, Universidade Federal do Amazonas.
}

\begin{abstract}
Resumo: O cará-roxo (Dioscorea trifida) é um produto amazônico cultivado para alimentação e muito conhecido na região norte. O objetivo deste trabalho foi utilizar o conhecimento tradicional sobre cará roxo como ferramenta facilitadora para a construção e desenvolvimento cognitivo da aprendizagem em Ciências. Esse trabalho foi aplicado para discentes do $9^{\circ}$ do Ensino Fundamental de uma escola rural no interior do estado do Amazonas, Brasil. A metodologia utilizada apresentou abordagem de caráter qualitativa através de observações, e quantitativa, com aplicação de questionário no início e no final. Houve aulas expositivas e aula experimental, onde os alunos relacionaram teoria com prática. Os resultados mostraram que o uso de cará roxo como indicador natural contribuiu para um aprendizado significativo, em que os alunos puderam ressignificar os conhecimentos tradicionais, despertando o interesse pela disciplina de Ciências. Todas as etapas foram executadas com êxito e contribuíram para valorização de um produto muito consumido na região e que demonstrou ser uma ferramenta eficiente para ser utilizada no ensino.
\end{abstract}

Palavras-chave: Dioscorea sp; Amazônia; Ácido e bases.

Abstract: The purple yam (Dioscorea trifida) is an Amazonian product used for food and well known in region. The objective of this work was to use empirical knowledge about cara yam as tool for construction and cognitive development of science learning. This work was applied to the 9th elementary school student at a rural school in country inside of Amazon state, Brazil. The methodology was qualitative and quantitative approach with observations and questionnaire at the beginning and at the end. There were expository classes and an experimental class, where students related theory to practice. The results showed that the use of purple yam as a natural indicator contributed to a significant learning, in which students were able to reframe empirical knowledge, arousing interest in the Science discipline. All steps were successfully performed and contributed to the valorization of a product that is widely consumed in the region and which proved to be an efficient tool to be used in teaching.

Keywords: Dioscorea sp; Amazon region; Acid and base.

Recebido em: $11 / 06 / 2021$

Aceite em: 14/08/2021 
Resumen: El ñame rojo (Dioscorea trifida) es un producto amazónico cultivado como alimento y muy conocido en la región norte. El objetivo de este trabajo fue utilizar el conocimiento tradicional sobre el ñame morado como herramienta facilitadora para la construcción y desarrollo cognitivo del aprendizaje en Ciencias. Este trabajo se aplicó a estudiantes de noveno grado de una escuela rural en el interior del estado de Amazonas, Brasil. La metodología utilizada presentó un enfoque cualitativo a través de observaciones y un enfoque cuantitativo, con la aplicación de un cuestionario al inicio y al final. Hubo clases expositivas y clases experimentales, donde los estudiantes relacionaron la teoría con la práctica. Los resultados mostraron que el uso del ñame morado como indicador natural contribuyó a un aprendizaje significativo, en el que los estudiantes pudieron replantear los conocimientos tradicionales, despertando el interés en la disciplina de Ciencias. Todos los pasos se llevaron a cabo con éxito y contribuyeron a la valorización de un producto de gran consumo en la región y que resultó ser una herramienta eficaz para ser utilizado en educación.

Palabras llave: Dioscorea sp; Amazonas; Ácidos y bases.

\section{INTRODUÇÃO}

O Ensino de Ciências permite explorar e despertar o interesse para as informações relacionadas aos fenômenos naturais, a sociedade, a tecnologia, à saúde e ao meio ambiente, favorecendo a construção e ampliação de novos conhecimentos e contribuindo para formação de cidadãos críticos, com capacidade de interpretar os fenômenos a sua volta e as transformações ocorridas (BRASIL, 2018; CHASSOT, 1990).

Um dos desafios do Ensino de Ciências consiste em criar um elo entre conhecimento científico e o cotidiano dos alunos, tornando-os autores no seu processo de aprendizagem e fazendo com que os conteúdos estudados em sala de aula tenham uma relação direta com as aplicações tecnológicas, ambientais, sociais, políticas e econômicas (SCHNETZLER, 1992; BRASIL, 2018; PERES, YAMAGUCHI, 2020).

Entre as metodologias didáticas capazes de contribuir com a aprendizagem dos discentes, destaca-se a contextualização como ferramenta usada para abordar conceitos científicos em um contexto socioeconômico relacionado aos fenômenos do cotidiano do estudante, valorizando os conhecimentos prévios de cada indivíduo (ALVES; RIBEIRO, 2020; SANTOS e MORTIMER, 1999; OLIVEIRA, 2010). Inserir práticas metodológicas diferenciadas podem estimular o interesse dos alunos e demostrar que o conhecimento obtido em sala de aula faz parte dos acontecimentos ocorridos no desenvolvimento do planeta e que se interligam as transformações observadas em atividades acadêmicas. 
Nesse cenário o presente trabalho visa apresentar a aplicação do uso dos conhecimentos tradicionais no ensino. Para tanto, a proposta foi de relatar a aplicação do extrato de cará-roxo (Dioscorea trifida) como ferramenta facilitadora no ensino e aprendizagem dos conteúdos de ácido-base em uma escola pública localizada em uma área rural no interior do estado do Amazonas.

Dioscorea trifida apresenta ampla distribuição nas Américas central e sul, desde as ilhas do Caribe até o Peru e no Brasil, distribui-se desde o Amazonas até a região sudeste (PEDRALLI, 1997). Este tubérculo (Figura 1) encontrado na flora amazônica é comumente usado na alimentação devido ao alto valor nutritivo e as propriedades biológicas, apresentando na sua composição diversas vitaminas do complexo B (tiamina, riboflavina, niacina), além das vitaminas A, vitamina C (ácido ascórbico) e carboidratos, principalmente em amido, além de apreciáveis teores de proteína e de gordura (Oliveira et al. 2007).
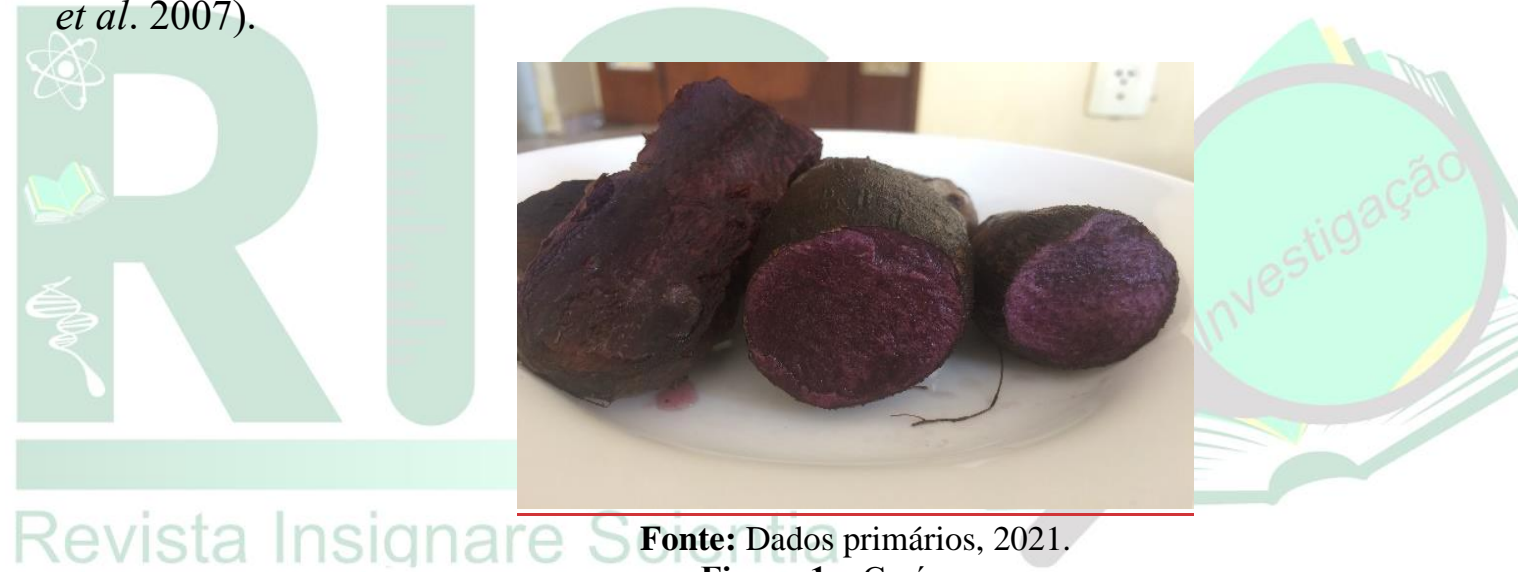

Fonte: Dados primários, 2021.

Figura 1 - Cará-roxo.

Esses tubérculos contêm pigmentos da classe de antocianinas que conferem a coloração que o nomeia popularmente e vêm sendo correlacionada a atividade antioxidante (HSU, 2004). Um estudo realizado por Nazaré (1998) mostrou que o extrato hidroalcóolico de cará-roxo, mostrou comportamento semelhante ao extrato de repolho roxo, (NAZARÉ, 1998; NAZARÉ et al., 1999).

\section{METODOLOGIA}

O Projeto foi realizado em uma Escola Municipal situada na comunidade São Francisco do Saubinha, área rural do município de Coari, distante a 444 km (quilômetro) da capital Manaus, estado do Amazonas. Para desenvolver o projeto na escola, realizouse testes prévios com o tubérculo do cará-roxo para testar sua eficácia como indicador. $\mathrm{O}$ método utilizado na extração de antocianinas foi por meio do tubérculo seco e triturado Recebido em: $11 / 06 / 2021$

Aceite em: 14/08/2021 
com solvente extrator etanol/água. Na extração foram utilizados os seguintes materiais: $72 \mathrm{~g}$ do tubérculo do cará-roxo (seco e triturado) $10 \mathrm{~mL}$ de etanol 96\% e $10 \mathrm{~mL}$ de água destilada. $\mathrm{O}$ extrato foi filtrado e armazenado no recipiente de vidro âmbar. Todos os testes e a produção do extrato foram realizados no Laboratório de Química Orgânica no Instituto de Saúde e Biotecnologia (ISB/UFAM) e podem ser visualizados por meio da Figura 2.

A comunidade rural é de difícil acesso devido a estrada estar em péssimas condições. O transporte usado pelos moradores e estudantes é o transporte público (ônibus) que faz a rota do município até a comunidade. A escola atende um público de crianças e adolescentes, filhos de trabalhadores de baixa renda, a maioria dos pais dos alunos são agricultores. Alguns professores são moradores da comunidade e outros fazem o percurso de Coari a comunidade.

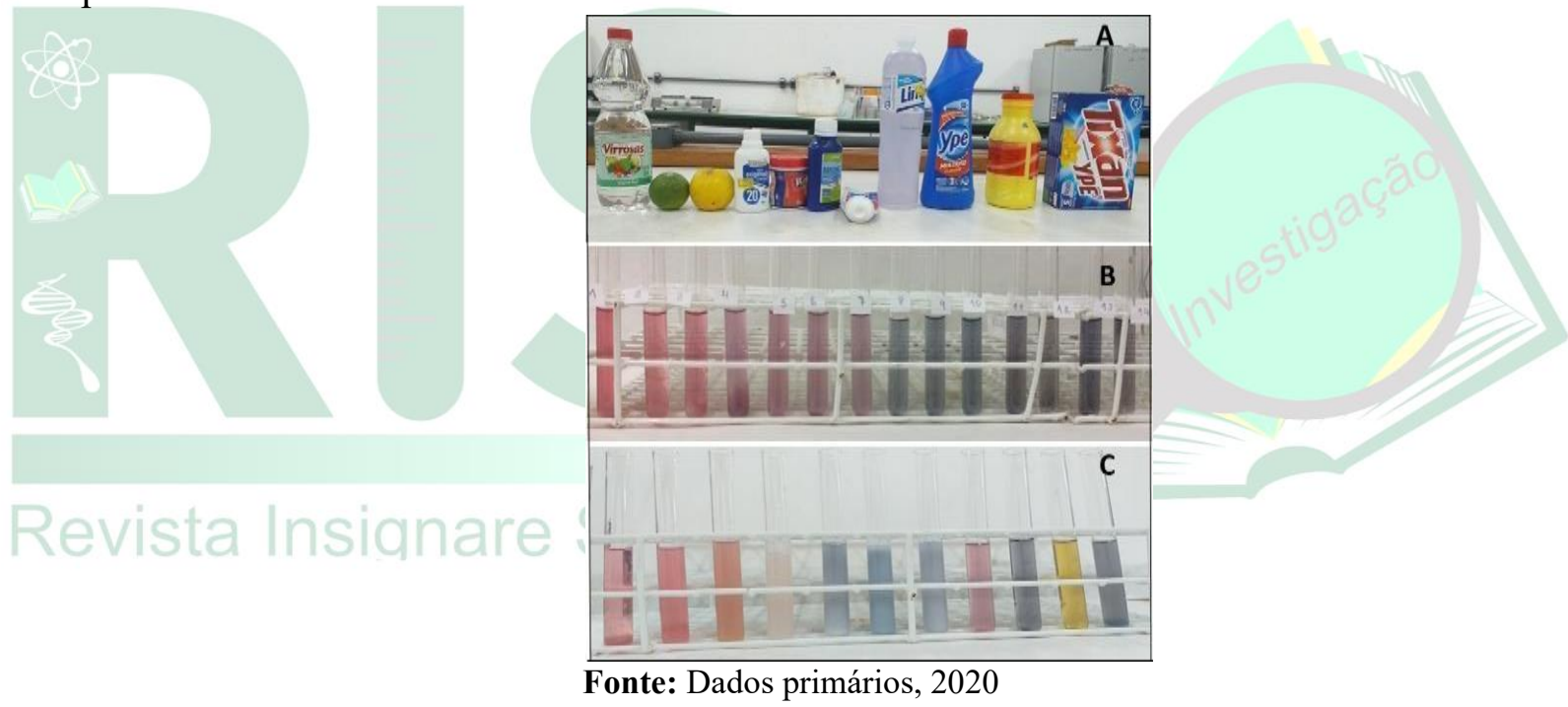

Figura 2 - Análise de cará como indicador ácido-base. A) Produtos utilizados; B) Escala de pH utilizando o extrato;

Nesse sentido, o trabalho configura-se em uma pesquisa qualitativa e quantitativa através de observações e aplicações de questionários semiestruturados. Os sujeitos da pesquisa foram os alunos do $9^{\circ}$ ano do Ensino Fundamental, na disciplina de Ciências. O projeto foi realizado para uma turma de 10 (dez) alunos no turno vespertino, com faixa etária de idade entre 14 e 21 anos.

Inicialmente foi aplicado um pré-questionário contendo 19 questões, sendo 18 questões objetivas e uma descritiva, com a intenção de compreender os conhecimentos prévios acerca de ácidos e bases, bem como do conhecimento tradicional sobre cará-roxo (Dioscorea trifida). Dentre as 19 questões, utilizou-se cinco, como comparativas, entre o 
pré e pós questionário. Os resultados obtidos foram tabulados, discutidos e apresentados em tabelas, com a utilização do programa Excel.

Durante a aplicação da atividade, realizou-se três aulas expositivas, todas com 90 minutos (dois períodos de aula, 45 minutos cada), com os seguintes assuntos:

$1^{\text {o }}$ aula: conceitos de Química em Ciências e a importância da Química para a sociedade. Em seguida, fez-se algumas questões indagativas aos alunos (o que é ácido e base? Você já comeu algum alimento ácido ou base? Você acha que ácidos e bases são perigosos?). Explanou-se sobre os conceitos e características de ácido e base, com ênfase na teoria (Arrhenius), citando exemplos de ácidos e bases do cotidiano.

$2^{\circ}$ aula: uso de indicadores, os tipos de indicadores (artificiais e naturais) especificando cada tipo de indicador e a escala de $\mathrm{pH}$ (potencial hidrogeniônico).

$3^{\text {o }}$ aula: iniciou-se indagando os discentes sobre os diferentes tipos de colorações de alguns frutos regionais, as antocianinas e em sequência, abordou-se sobre as características e as propriedades de tubérculo cará-roxo (D. trifida).

Os recursos utilizados nas aulas foram computador, multimídia, pincel e quadro branco. Buscou-se a interação da turma através de resolução de atividade no quadro. As atividades englobaram os conceitos de ácido e base e as propriedades e uso do cará-roxo, de forma simples e objetiva para compreensão do assunto.

$\mathrm{Na}$ aula experimental utilizou-se como indicador natural de ácido e base o extrato de cará-roxo. Elaborou-se um roteiro da aula prática, de forma simples e objetiva, que serviu para facilitar nas orientações aos alunos sobre os procedimentos a serem realizados. A aula proporcionou trabalhar com materiais de laboratório (béquer, tubos de ensaio, pipetas, pissetas), disponibilizados pelo Laboratório de Química Orgânica do Instituto de Saúde e Biotecnologia (ISB/UFAM) e materiais alternativos (copo de plástico, seringas descartáveis, funil de plástico, colher), demonstrando a possibilidade de adaptação. Utilizou-se produtos de fácil acesso e de baixo custo presente no cotidiano dos alunos, a saber: vinagre, creme dental, fermento industrial, soda cáustica, detergente, leite de magnésia e sabão em pó e frutos como: limão, acerola, laranja, camu-camu e bacuri.

Os discentes identificaram os produtos ácidos, básicos e neutros e organizaram a escala de $\mathrm{pH}$ em ordem crescente de acidez. As quantidades de produtos utilizados e todos os procedimentos necessários estão no roteiro da aula prática, em anexo. Após a realização das aulas, teórica e prática, foi aplicado o pós- questionário contendo 14 questões, buscando informações sobre as contribuições das atividades realizadas. 


\section{RESULTADOS E DISCUSSÃO}

No questionário inicial pode-se analisar o conhecimento prévio dos discentes sobre o assunto de ácido e base e sobre o tubérculo cará-roxo (Tabela 1) . Verificou-se que 70\% dos alunos, consideram os conteúdos de Ciências/Química parcialmente difícil e cerca de $50 \%$ dos alunos definiram os conhecimentos na disciplina de Ciência como "bom".

Tabela 1 - Questionário inicial.

\begin{tabular}{|c|c|c|c|}
\hline Pré-questioná & & & \\
\hline Questões & Respostas & $\mathbf{N}$ & $\begin{array}{c}\text { Percentual } \\
(\%)\end{array}$ \\
\hline 1. Os conteúdos de Química, na disciplina de & Não & 3 & 30.0 \\
\hline Ciências são difícil? & Parcialmente & 7 & 70.0 \\
\hline 2. Como você considera seus conhecimentos na & Ruim & $\underline{2}$ & 20.0 \\
\hline disciplina de Ciências/ Química? & Regular & $\underline{3}$ & 30.0 \\
\hline $808-2$ & Bom & 5 & 50.0 \\
\hline 3. Você consegue relacionar os assuntos de & Sim & 3 & 30.0 \\
\hline Ciências com seu dia- dia? & Não & $\underline{5}$ & 50.0 \\
\hline & Parcialmente & 2 & 20.0 \\
\hline 4. Você já estudou sobre ácidos e bases? & Não & 10 & 100.0 \\
\hline $\begin{array}{l}\text { 5. Você sabe como diferenciar um ácido de uma } \\
\text { base? }\end{array}$ & Não & 10 & 100.0 \\
\hline & Doce & 1 & 10.0 \\
\hline 6. Quais das alternativas, & Azedo & $\underline{2}$ & 20.0 \\
\hline característica de um ácido? $\cap 2 \mathrm{re}^{\mathrm{C}}$ & Ardoso & $\underline{3}$ & 30.0 \\
\hline Não sei & & 4 & 40.0 \\
\hline & Doce & 1 & 10.0 \\
\hline 7. Quais dessas alternativas tem característica de & Sem gosto & 1 & 10.0 \\
\hline base? & Azedo & $\underline{1}$ & 10.0 \\
\hline Não sei & & 7 & 70.0 \\
\hline $\begin{array}{l}\text { 8. Quais dos produtos são ácido ou base? } \\
\text { Coloque } \mathbf{A} \text { para ácido e } \mathbf{B} \text { para base. }\end{array}$ & Acertos & 60 & 50.0 \\
\hline & Erros & 60 & 50.0 \\
\hline 9. Você já teve aula & Sim & $\underline{3}$ & 30.0 \\
\hline experimental? & Não & 7 & 70.0 \\
\hline 10. Você já utilizou materiais alternativos em & Sim & 2 & 20.0 \\
\hline & Não & 8 & 80.0 \\
\hline 11. Você acha que matéria prima (frutos, & Sim & 7 & 70.0 \\
\hline vegetais etc) poderia ser utilizados na disciplina & Não & $\underline{1}$ & 10.0 \\
\hline $\begin{array}{l}\text { de } \\
\text { Ciências/Química? }\end{array}$ & Parcialmente & 2 & 20.0 \\
\hline $\begin{array}{l}\text { 12. Você conhece o cará-roxo (Dioscorea } \\
\text { trifida)? }\end{array}$ & Sim & 10 & 100.0 \\
\hline 13. Quais os tipos de cará você conhece? & $\begin{array}{c}\text { Cará-branco e } \\
\text { Cará-roxo }\end{array}$ & 7 & 70.0 \\
\hline
\end{tabular}

Recebido em: $11 / 06 / 2021$

Aceite em: 14/08/2021 


\begin{tabular}{|c|c|c|c|}
\hline & Cará-roxo & 2 & 20.0 \\
\hline \multirow{3}{*}{$\begin{array}{l}\text { 14. Você gosta de comer cará? } \\
\text { Gosto pouco }\end{array}$} & Gosto & 7 & 70.0 \\
\hline & Não gosto & 1 & 10.0 \\
\hline & & 2 & 20.0 \\
\hline \multirow{3}{*}{$\begin{array}{l}\text { 15. Como você consome o cará? } \\
\text { Não consumo }\end{array}$} & Cozido & 8 & 80.0 \\
\hline & Na comida & 4 & 40.0 \\
\hline & & 1 & 10.0 \\
\hline \multirow{4}{*}{$\begin{array}{l}\text { 16. Em qual local você encontra com mais } \\
\text { frequência cará-roxo? }\end{array}$} & Sítio & 6 & 60.0 \\
\hline & Feira & 4 & 40.0 \\
\hline & Quintal & 4 & 40.0 \\
\hline & $\begin{array}{c}\text { Vizinhos/Casa de } \\
\text { familiares }\end{array}$ & 2 & 20.0 \\
\hline
\end{tabular}

Fonte: Dados primários (2021).

Ao questionar os alunos, se conseguiam relacionar os conteúdos de Ciências/Química com o cotidiano, cerca de $70 \%$ relataram que não conseguem fazer essa relação. Segundo Penaforte e Santos (2014), um dos fatores que interfere no aprendizado e na assimilação de conteúdos, é a falta de contextualização em Ciências, ocasionando a rejeição e o desinteresse pela disciplina, dificultando o processo de aprendizagem. Sobre as aulas experimentais, cerca de $70 \%$ dos alunos, responderam que não, bem como, não utilizam materiais alternativos. Esses resultados podem decorrer de fatores a exemplo: a falta de recurso, tempo do professor, a falta de espaço adequado ou dificuldade em elaborar a aula.

A falta de atividades experimentais devido, por vezes, a escassez de recursos, é descrita por vários estudos. Para tanto, o uso de experimentos alternativos e acessíveis são úteis para sanar essas dificuldades (SILVA et al., 2009).

Ao indagar se estudaram sobre ácido/base e se sabiam diferenciar um ácido de uma base, as respostas foram idênticas para essas questões, $100 \%$ dos alunos disseram que não estudaram esse conteúdo e não sabiam como diferenciar um ácido de uma base. Ao perguntar quais as características de um ácido e uma base, 40\% não sabiam a característica de ácido e $70 \%$ não sabiam a característica de uma base. Para classificar produtos do cotidiano (vinagre, creme dental, fermento industrial, soda cáustica, detergente, leite de magnésia, sabão em pó, limão, acerola, laranja, bacuri e água) em ácido ou base, $50 \%$ dos alunos acertaram na classificação do produto e $50 \%$ erraram. Esses resultados demostram que os alunos não haviam estudado o conteúdo de ácidos e bases, mas que apresentavam uma noção empírica sobre o tema. Segundo a grade 
curricular do Ensino Básico, o assunto de ácido e base deve ser estudado no $9^{\circ}$ ano do ensino fundamental e posteriormente no $1^{\circ}$ ano do ensino médio (BRASIL, 2018).

Ao perguntar, se nas aulas de Ciência/Química poderiam ser utilizadas matérias primas (frutos e vegetais), 70\% dos(as) alunos(as) responderam que sim. De acordo com Cuchinski, Caetano e Dragunski (2010) os extratos de plantas e frutos podem ser uma alternativa simples e de baixo custo, para auxiliar no processo de ensino e aprendizagem de Ciências, tornado o conhecimento mais interessante.

O questionário referente ao conhecimento tradicional dos alunos sobre cará-roxo (D. trifida), demostrou os seguintes resultados: 100\% dos alunos conhecem o tubérculo cará-roxo; $70 \%$ dos alunos conhecem as variedades, cará-branco (D. alata) e o cará-roxo (D. trifida); nenhum dos alunos sabia a composição química. Diante desses resultados, percebeu-se que o tubérculo faz parte do ambiente dos discentes e é bastante consumido, porém pouco conhecido em relação aos dados científicos e acadêmicos.

As aulas expositivas possibilitaram a demonstração de exemplos em figuras ilustrativas para adensar a compreensão do assunto. Houve a participação dos alunos em todos os momentos. Observou-se que os alunos prestavam atenção nos conteúdos e aos poucos a turma foi interagindo, conforme o andamento das aulas.

Através de alguns exemplos apresentados sobre ácido e bases e suas aplicações no cotidiano, os alunos começaram a descobrir que esse assunto não estava distante do seu dia a dia. Dessa forma, cabe ao professor criar um ambiente motivador, com metodologias diferenciadas e usar recursos adequados, pois quando bem empregados, aumentam a possibilidade de assimilação de conhecimento e aprendizagem (CARVALHO, 2006).

Segundo Castoldi e Polinarski (2009), o professor deve criar estratégias para que o aluno não assimile o conteúdo como uma cobrança de aprendizado, mas sim, como uma troca de informações e experiências para a construção do conhecimento.

Após as aulas teóricas realizou-se a atividade experimental na sala de aula, proporcionando aos estudantes aplicar na prática, o que foi estudado em teoria. Essa foi uma estratégia utilizada para contextualizar, articular os assuntos e contribuir com a melhoria no ensino de Ciências.

Nessa direção, foram dadas orientações aos alunos, dando ênfase no cuidado e atenção ao manusear os materiais. Os alunos cumpriram cada etapa como: diluir substância, transferir para tubos de ensaio, mensurar o volume necessário de cada 
produto. Cada grupo observou a ação do indicador utilizado nas soluções. Em soluções ácidas, o indicador apresentou coloração para tons vermelhos (limão, vinagre, acerola, laranja e bacuri); produtos com caraterísticas básicas apresentaram coloração azul esverdeado e amarelo (alvejante, creme dental, fermento industrial, leite de magnésia, sabão em pó e soda cáustica) e substância de finalidade neutra (água), possuiu coloração da cor do extrato, coloração roxa.

A maioria dos discentes obteve pela primeira vez o contato com essa técnica didática de ensino. Observou-se que essa estratégia didática despertou a atenção e a interação dos alunos durante aula. Segundo Carvalho (2006), existem diversos materiais encontrado na natureza e que podem ser usados como ferramenta de estudo, tais como: extrato de repolho roxo, flores, beterraba, açaí entre outros, como substitutos baratos e facilmente acessível de indicadores ácido e base.

As aulas experimentais podem ser trabalhadas com diferentes objetivos, buscando sempre contribuir com o processo de ensino e aprendizagem em Ciências, desde estratégias que se observam a simples ilustração ou a verificação de teorias, até aquelas que incentivam a criatividade dos alunos, oferecendo condição para refletirem a respeito dos fenômenos científicos (OLIVEIRA, 2010).

Os alunos verificaram a escala de $\mathrm{pH}$ (potencial hidrogeniônico) de cada solução através da fita de $\mathrm{pH}$, que é uma ferramenta de teste quantitativo para indicar acidez, basicidade ou substâncias neutras. A escala de $\mathrm{pH}$ ocorre da seguinte forma, soluções que apresentam pH 7, são consideradas neutras, e as com pH menor que 7 são consideradas ácidas e aquelas com pH maior que 7 são básicas.

Os alunos imergiram a fita em cada substância e verificaram o índice quantitativo da solução investigada. No início alguns tiveram dificuldade para definir a coloração que aparecia na fita, mas posteriormente, conseguiram mensurar a escala de cada produto. A escala de $\mathrm{pH}$ é medida de 0 a 14, onde podemos determinar a acidez e a basicidade presentes nas soluções (MACEDO, 2000).

Utilizou-se alguns materiais de laboratório (béquer, tubos de ensaio, pipetas, pissetas) para possibilitar aos discentes conhecerem as vidrarias e, fez-se uso de materiais alternativos (copo de plástico, seringas descartáveis, funil de plástico, colher) para demonstrar as possíveis adaptações. Observou-se o entusiasmo dos alunos quando as soluções mudavam de coloração ao adicionar o extrato do cará-roxo. Todos conseguiram 
classificar as soluções e montaram a escala de $\mathrm{pH}$ dos produtos em ordem crescente, mais ácido ao mais básico, sem dificuldade.

O experimento proporcionou momentos únicos de aprendizado, uma vez que os alunos trabalharam em equipe com mútua participação, interlocução de saberes, troca de conhecimentos adquiridos e desempenho coletivo. Segundo Prigol e Giannotti (2008), a aula prática ajuda no desenvolvimento dos conceitos científicos, além de permitir que os alunos aprendam correlacionar o assunto com cotidiano, situando-os no contexto socioeconômico e cultural e contribuindo para o despertar do saber científico.

Após as atividades do projeto, aplicou-se o pós-questionário, para averiguar $\mathrm{o}$ desenvolvimento adquirido com o projeto. Os resultados e as questões são demostrados na Tabela 2.

Tabela 2 - Questionário final

\begin{tabular}{|c|c|c|}
\hline & Respostas & Percentual (\%) \\
\hline $\begin{array}{l}\text { 1. A ferramenta utilizada (cará-roxo), ajudou você em } \\
\text { seus conhecimentos de ácido e base? }\end{array}$ & Sim & 100.0 \\
\hline \multirow{2}{*}{$\begin{array}{l}\text { 2. A experimentação utilizada contribuiu para o seu } \\
\text { aprendizado? }\end{array}$} & Sim & 80.0 \\
\hline & Parcialmente & 20.0 \\
\hline $\begin{array}{l}\text { 3. Quais desses produtos são ácido ou base. Coloque } \mathrm{A} \\
\text { para ácido, B para base e } \mathrm{C} \text { para neutro? }\end{array}$ & Acertos & 100.0 \\
\hline \multirow[t]{2}{*}{ 4. Você sabe como diferenciar um ácido de uma base? } & +2 & 90.0 \\
\hline & Não & 10.0 \\
\hline 5. Indique para que serve o indicador natural? & $\begin{array}{l}\text { Indicar se a solução é ácida, } \\
\text { básica ou neutra. }\end{array}$ & 100.0 \\
\hline \multirow{2}{*}{$\begin{array}{l}\text { 6. Por que o tubérculo do cará- roxo pode ser usado como } \\
\text { indicador? }\end{array}$} & Porque tem antocianinas. & 90.0 \\
\hline & Porque tem proteínas. & 10.0 \\
\hline $\begin{array}{l}\text { 7. Antes do projeto, você já sabia que o tubérculo do } \\
\text { cará-roxo, pode ser utilizado como indicador } \\
\text { natural? }\end{array}$ & Não & 100.0 \\
\hline \multirow{2}{*}{$\begin{array}{l}\text { 8. Você gostou de aprender Ciências/Química, utilizando } \\
\text { um produto da região Amazônica? }\end{array}$} & Gostei muito & 90.0 \\
\hline & Gostei pouco & 10.0 \\
\hline $\begin{array}{l}\text { 9. Você gostaria de ter mais aula de Ciências/Química, } \\
\text { utilizando produtos (frutas, plantas etc.) amazônicos? }\end{array}$ & Sim & 100.0 \\
\hline 10. Em que aula você entendeu o assunto? & Aula teórica e prática & 100.0 \\
\hline \multirow[t]{3}{*}{ Você sabe a composição quí } & Sim & 80.0 \\
\hline & Não & 10.0 \\
\hline & Parcialmente & 10.0 \\
\hline \multirow{3}{*}{ 12. Como você avalia a aula teórica? } & Regular & 10.0 \\
\hline & Boa & 50.0 \\
\hline & Excelente & 40.0 \\
\hline \multirow[t]{3}{*}{ 13. Como você avalia a aula prática? } & Boa & 10.0 \\
\hline & Excelente & 90.0 \\
\hline & "Gostei muito" & 30.0 \\
\hline
\end{tabular}


Fonte: Dados primários (2021).

$\mathrm{Na}$ análise da atividade, verificou-se uma alta aceitabilidade, onde $90 \%$ dos discentes gostaram de aprender Ciências com produto da região e 100\% gostariam de ter mais aulas utilizando aulas contextualizadas. Diante das respostas percebe-se que a inserção de temas geradores nas metodologias de ensino de Química que são aplicáveis no cotidiano, contribuem no processo de ensino e aprendizagem dos educandos (GOMES; DANTAS FILHO 2021).

Os alunos entenderam o conteúdo nas aulas teóricas e prática com percentual de $100 \%$. Observar-se que a maioria dos alunos entenderam os assuntos na aula teórica e conseguiram correlacionar com a aula prática, mostrando que as duas aulas contribuíram para um aprendizado significativo. De acordo com Macedo (2000), uma das formas de ocorrer a aprendizagem relaciona-se com a interação dos conhecimentos novos e os conhecimentos prévios dos alunos.

Verificou-se com isso que o projeto contribuiu para o ensino de Ciências com a aplicação de um produto Amazônico aplicado ao conteúdo de ácido e bases. Espera-se que novos projetos com esse viés possam acontecer, valorizando os conhecimentos populares e ressignificando os conceitos teóricos das disciplinas.

\section{CONCLUSÃO}

A proposta favoreceu no entendimento do assunto com resultados promissores, uma vez que os alunos mostraram interesse nas atividades propostas e observou-se o desenvolvimento de aprendizado e construção de novos conhecimentos. Nas aulas teóricas e experimentais os alunos assimilaram os conteúdos, mas a interação maior foi vista na aula experimental, com troca de saberes, interesse e também, com aprendizagem colaborativa entre os grupos. Assim, ressalta-se a valorização do conhecimento tradicional dos discentes relacionando conhecimento científico e conhecimento empírico como forma de valorização das experiências cotidianas e conservação da cultura local.

A ferramenta usada pode ser inserida no Ensino Fundamental, Médio e até mesmo no Ensino Superior, mostrando aos aprendizes meios viáveis de se trabalhar com esse assunto. Assim, verificou-se que a utilização de materiais do cotidiano facilitou no 
aprendizado e a contextualização oportunizou aproximar os conhecimentos teóricos da realidade dos alunos.

\section{REFERÊNCIAS}

BRASIL. Base Nacional Curricular Comum, 2018. Acesso em: http://basenacionalcomum.mec.gov.br/ .Disponível em 18/6/2021.

CARVALHO, V. F. Atividades práticas de biologia desenvolvidas em sala de aula da EJA. In: encontro regional sul de ensino de biologia, 2.; jornada de licenciatura em ciências biológicas da ufsc, 3., Florianópolis, Anais. Florianópolis, p. 2-8, 2006.

CASTOLDI, R., POLINARSKI, C. A. Considerações sobre estágio supervisionado por alunos licenciandos em Ciências. In: VII Encontro Nacional de Pesquisa em Educação em Ciências, Florianópolis, Anais do VII ENPEC, Belo Horizonte: ABRAPEC, 2009. HASSOT, A. L. Alfabetização Cientifica: questões e desafios para a educação. 117 p. São Paulo: editora LJUÍ, 1990.

CUCHINSKI, A.S., CAETANO, J., DRAGUNSKI, D.C. Extração do corante da beterraba (Beta vulgaris) para utilização como indicador ácido base. Ecletica Química, v.35, n. 4, p. 17-23, 2010.

GOMES, J. PEREIRA; DANTAS FILHO, F. Ensino de Química na Educação Básica: Construindo Conhecimentos a partir da produção do Sabão. Revista Insignare Scientia RIS, v. 4, n. 4, p. 249-269, 20 jun. 2021.

MACEDO, M. U.; CARVALHO, A. Química: Coleção Horizonte. Cidade: Fortaleça / CE. Editora IBEF, 2000.

NAZARÉ, R.F.R. de; ALVES, S. de M.; BARBOSA, W.C.; RODRIGUES, I.A.; FARIA, L. J. G.; KUSUHARA, K. Estudo para identificação de vegetais produtores de corantes, ocorrentes na flora amazônica. In: EMBRAPA. Centro de Pesquisa Agroflorestal da Amazônia oriental. Geração de tecnologia para o desenvolvimento do Trópico Úmido. Belém-PA, 1999.

NAZARÉ, R.F.R. Obtenção e aplicação de corantes naturais. In FARIA, L.J.G. de; COSTA, C.M.L. (Coord.). Tópicos especiais em tecnologia de produtos naturais. Belém: UFPA/NUMA/POEMA. p.332, 1998.

OLIVEIRA, A.P., BARBOSA, L. J. N., PEREIRA, W.E., SILVA, J.E.L., OLIVEIRA, A. N. P. Produção de túberas comerciais de inhame em função de doses de nitrogênio. Brasília. Horticultura Brasileira, v.25, n.1, p. 73-76, 2007.

OLIVEIRA, J. R. S. A Perspectiva Sócio-histórica de Vygotsky e suas relações com a Prática da Experimentação no Ensino de Química. Alexandria - Revista de Educação em Ciências e Tecnologia, v.3, n.3, p. 25-45, 2010. 
PEDRALLI, G. Revisão taxonômica das espécies de Dioscoreaceae (R.Br.) Lindley da Cadeia do Espinhaço, Minas Gerais e Bahia, São Paulo. Tese doutorado PG - Botânica, Universidade de São Paulo (USP), São Paulo. p. 500, 1997.

PENAFORTE, G. S., SANTOS, V. S. O ensino de química por meio de atividades experimentais: aplicação de um novo indicador natural de $\mathrm{pH}$ como alternativa no processo de construção do conhecimento no ensino de ácidos e bases. Revista Educação, sociedade e ambiente, v.1, n. 2, p.8-21, 2014.

PERES, E. G.; YAMAGUCHI, K. K. L. A farinha de mandioca e as relações CiênciaTecnologia-Sociedade-Ambiente (CTSA) como valorização do conhecimento tradicional no ensino de ciências. Revista Insignare Scientia - RIS, v. 3, n. 5, p. 439-455, 2020.

PRIGOL, S., GIANNOTTI, S. M. Importância da utilização de práticas no processo de ensino-aprendizagem de Ciências naturais enfocando a morfologia da flor. $\mathbf{1}^{\mathbf{0}}$ Simpósio Nacional de Educação e XX semana de Padagogia, nov, 2008.

SANTOS, W. L., MORTIMER, E. F. A dimensão social do ensino de química-um estudo exploratório da visão dos professores. In:II Encontro Nacional de pesquia em Educação em ciências. Valinhos. 1999.

SCHNETZLER, R. P. Construção do Conhecimento e Ensino de Ciências. Em Aberto, v. 11. n. 55, p. 17-22, 1992.

SILVA, R. T. DA., CURSINO, A. C.T., ARIRES, J. A., GUIMARÃES, O. M. Contextualização e Experimentação, Uma Análise dos Artigos Publicados na Seção 16 "Experimentação no Ensino de Química" da Revista Química Nova na Escola 20002008. Ensaio - Pesquisa em Educação em Ciências, v. 11, n. 2, p. 1-22, 2009. 